\title{
Non-Keratinizing Dysplasia
}

National Cancer Institute

\section{Source}

National Cancer Institute. Non-Keratinizing Dysplasia. NCI Thesaurus. Code C161016.

Epithelial dysplasia in which there is continuum from mild dysplasia to moderate dysplasia to severe dysplasia before the development of invasive carcinoma. 